\title{
Making Positive Impacts on Self-Determination via the National Center and State Collaborative Initiative
}

\author{
Stephanie D. Davis \\ College of Education \\ Middle Tennessee State University, USA
}

\begin{abstract}
Self-determination is an important measure of learning for students with significant cognitive disabilities. The purpose of this study was to determine whether the mean scores of two components of self-determination (capacity and opportunity) differed for students with significant cognitive disabilities that had participated in the National Center and State Collaborative Curriculum Resource Schema intervention. Research participants included seven students with significant cognitive disabilities, their parents, and teacher. Self-determination was measured using the American Institutes for Research (AIR) Self-Determination Assessment, which focused on capacity and opportunity. A one-group pretestposttest design was used to collect information on the status of subjects prior to and following the intervention. The differences between the posttest and pretest means for the components capacity and opportunity were determined. The results of this study contribute to the research knowledge of the learning theory of self-determination. Implications of the results and suggestions for future research are discussed.
\end{abstract}

\section{Introduction}

This purpose of this study was to determine if the National Center and State Collaborative Curriculum Resource Schema intervention created a difference in the self-determination mean scores of students with significant cognitive disabilities. A positive change would result in increased college, career, and community readiness for these students. There is an intensified emphasis for students with disabilities to exit high school with skills that will enable them to be college, career, and community ready. Selfdetermination must be an educational objective if these students are expected to achieve this measure.

Wehmeyer and Schwartz [17] reported that students who possess self-determination have a stronger chance of being successful in making the transition to adulthood, including employment and independence. Their research supports the view that self-determination is related to positive transition outcomes. Self-determination refers to the characteristics of a person that leads the individual to make choices and decisions that are based on preferences and interests. It also allows individuals to monitor and control their actions and to be goaloriented and self-directing [12]. The goal for educators must be to create learning conditions that foster selfdetermination in students with disabilities.

The National Governors Association and Council for Chief State School Officers introduced the Common Core State Standards (CCSS) in 2010. These standards seek to prepare students for college, career, and community readiness. States are allowed to develop an alternate assessment based on alternate achievement standards (AA-AAS) for students with the most significant cognitive disabilities (SCD). The U.S. Department of Education awarded the National Center and State Collaborative (NCSC) a grant to develop a new AA-AAS for students with the most SCD. The full-scale NCSC project is led by five centers and twenty-four states to build an alternate assessment based on alternative achievement standards for students with the most SCD [10].

The NCSC developed the Learning Progressions Frameworks (LPF) for use with the CCSS. The LPF describe how the understanding of core concepts in English Language Arts and Mathematics typically develop over time when students have the benefit of high quality instruction. These frameworks offer a guide to instruction, and assist educators in lesson planning by linking instruction to CCSS through Core Content Connectors (CCC). According to the National Center and State Collaborative [10] CCC pinpoint the most relevant grade-level, core academic content in English Language Arts and Mathematics found in the Common Core State Standards. The CCC explain the necessary knowledge and skills needed to reach the learning targets that are within the LPF and the CCSS. The implementation of this curriculum resource schema is believed to allow students with disabilities to achieve at higher levels of learning because the CCC are based CCSS derived from the student's grade level. Higher levels of achievement are needed in order for students to possess self- determination that will prepare them for college, career, and community readiness.

Research has not been conducted to determine if 
the NCSC Curriculum Resource Schema intervention will positively impact the selfdetermination of students with SCD. If students with SCD are expected to leave high school with skills that enable them to be college, career, and community ready, then research must be conducted to determine if NCSC Curriculum Resource Schema intervention will produce the self-determination that will enhance successful transitions into adulthood, including the employment and independence that Wehmeyer and Schwartz [17] allude to.

\section{Review of Literature}

The educational practices for students with SCD have evolved as research has been utilized to guide best practices. During the 1970s, Brown, Bronston, Hamre-Nietupski, Pumpian, Certo, and Gruenewald [1] challenged the field of special education to focus on age appropriate skills for students as opposed to basing instruction on the student's mental age. In the years following, researchers and practitioners began to shift from a life skills focus to skills related to community and social interactions [13]. Next, the research shifted to academic learning [2]. Finally, as educators began to incorporate standards-based instruction, an emphasis was placed on teaching grade level content skills [3 \& 7]. These findings are relevant to the implementation of the NCSC, because it is an approach to instruction and assessment that seeks to connect students with SCD to the appropriate grade level standards of learning.

The objective of the NCSC is to ensure that students with SCD achieve higher academic outcomes that will enable them to be college, career, and community ready. Not every student with SCD will be able to achieve this goal. However, every student should have the opportunity to try. Academic instruction designed to enhance college, career, and community readiness promotes improvements in skills needed to be part of a community.

These skills include communication, math and reading, independent and team work skills, social skills, and skills for identifying and requesting supports [10]. Curricular materials have been developed to assist teachers in presenting content to improve college, career, and community readiness skills. This content is presented as curriculum resources, and will be assessed in the NCSC assessment.

It is crucial that teachers hold high expectations for students with SCD, and embrace new research concerning individual capabilities. Exposure to academic content, in natural settings, has proven to enhance quality of life and prepare students for college, career, and community readiness [6]. The NCSC seeks to provide academic content exposure in natural settings with the application of the curriculum resources. In the early 1990s Maryland and Kentucky initiated the inclusion of students with SCD into the school accountability analyses. The research derived from their efforts led Ysseldyke and Olsen [19] to reveal four assumptions concerning assessments of students with SCD.

These four assumptions shaped the early development of alternative assessments, and continue to be evident in state assessments today. The first assumption reveals that there must be a focus on authentic skills. The researchers felt that assessments conducted in artificial environments do not portray an accurate picture of how well the system was preparing the student. They noted that environment, or community, varies for each individual student. These environmental variances need to be calculated into instructional designs. The second assumption focuses on measurement of skills across various domains. For students with SCD, learning of specific skills must occur intentionally alongside other relevant skills. The focus on intentional integration of skills must also carry over into assessment of students with SCD. The third assumption concentrates on the use of a continuous documentation method if possible. The researchers noted that students with SCD have greater variability in their skills from day to day. An assessment that includes multiple measures occurring over time will yield more precise and reliable results. The final assumption places the burden on the school system to provide the needed supports and adaptions to the students program planning. Ysseldyke and Olsen [19] reiterated the accountability of the educational system to provide these needed supports to ensure that the students are able to function as independent as possible.

New ideas concerning assessment of students with SCD have come to surface since the introduction of these four basic assumptions in 1997. However, Quenemoen [14] reported that a review of state survey data suggests that numerous states continue to see these assumptions as imperative to consider in development of alternate assessments. Recent initiatives have sought to increase the standards of academic and assessment expectations for students with SCD. The expectation of these increased demands will yield results that reveal a more accurate picture of how well students are performing on age appropriate standards based instruction.

One challenge in alternate assessments has been 
the incorporation of scientifically based research surrounding best practices for teaching academic skills to students with SCD. The research conducted by Snell [15] revealed that there is minimal guidance for educators to teach reading, math, and science skills to students with SCD, but there is considerable research related to teaching functional life skills. In order for students with SCD to become college, career, and community ready, they must become proficient in academic skills also.

\subsection{Federal Policy Historical Context for Alternate Assessments}

The Federal impact on alternate assessments can be seen with 1997 amendments to The Individuals with Disabilities Education Act (IDEA). The preamble to IDEA 1997 contained a declaration by Congress that recognized that historically, "the implementation of this Act has been impeded by low expectations and an insufficient focus on applying replicable research on proven methods of teaching and learning for children with disabilities" [14]. Additionally, the report noted that research and practice demonstrated that the education of children with disabilities is more effective when high expectations are anticipated and exposure to the general education setting is maximal. The curriculum design of the NCSC is in alliance with the report, as it seeks to raise academic expectations for student with SCD. The IDEA was the first federal requirement of alternate assessments for students with SCD. The 1997 amendment to IDEA redefined what students should know and be able to do. However, with the amendment, students with disabilities were required to show progress in the same curriculum as their peers. At the time, many did not recognize the significance of the culture shift that this reformation initiated. States began redefining "the maximum extent possible" described in the IDEA preamble for all students with disabilities, even the students with SCD.

Thompson and Thurlow [16] identified a few factors that affected the development of alternate assessment during the early days of its initiation. First, most states developed the overall approach and format of the alternate assessment in partnership with general and special educators, along with parent representatives from the state special education advisory committees or parent organizations. Second, functional based instruction versus academic based instruction served as a tension in design of alternate assessments. Lastly, the report identified the challenges that state assessment offices were having in understanding how this different type of largescale test could be scored and reported with reliability. Unfortunately, the alternate assessment was generally perceived as problematic and a situation that needed to be resolved by special education [8]. The NCSC has developed an approach to instruction and assessment that seeks to support families, educators, and administrators as they seek to prepare students with SCD for college, career, and community readiness.

\section{Methodology}

\subsection{Participants}

All students within the Transitional Comprehensive Developmental Classroom (CDC) in an elementary school in rural Tennessee were eligible to participate in this study. However, only seven students agreed to take part in the research. The ages of students ranged from five to ten years. The specific disabilities included autism, developmental disabilities, intellectual disabilities, and other health impaired.

\subsection{Procedures}

The purpose of this research was to determine if the mean scores for capacity and opportunity on the pretest AIR Self-Determination Assessment differ from the mean scores of the posttest AIR SelfDetermination Assessment for students with SCD, after the intervention of the NCSC Curriculum Resource Schema was applied. For analysis, a one group pretest-posttest design was conducted. The pretest data were compared to posttest data after a nine week intervention phase was completed. The results are separated into three sections, Student Responses, Parent Responses, and Educator Responses. In each section, the mean of responses linked to capacity, opportunity, and (+/-) change differences for self- determination is recorded from the individual groups of respondents.

The intervention consisted of the teacher following the guidelines of NCSC Curriculum Resource Schema. These guidelines and resources can be found on the NCSC Wiki website [11]. Lessons were designed to maximize learning opportunities by connecting them to grade-level content. Additionally, needed accommodations and systematic evidence-based instructional strategies were applied to the academic lessons. The principles of universal design for learning (UDL) provided a framework upon which lessons were built. The UDL offered multiple ways to teach the content, multiple ways for students to demonstrate knowledge, and multiple ways to engage all learners. Next, 
curriculum was modified to link instruction to CCSS. The NSCS model calls for a prioritized portion of the CCSS to support access to the general education curriculum in each grade, at reduced depth, breadth, and complexity when necessary.

The NCSC contains two tools which assisted in the planning process, the LPF and the CCC. The CCC were utilized in each lesson to create deeper understandings. These CCC are specifically intended to promote the success needed for students with SCD to advance to the next grade. They are the starting point for instruction, not necessarily everything an individual student can and should learn. This basic framework of the NCSC Curriculum Schema was implemented as the intervention for this research study.

The AIR Self-Determination Assessment measures two broad self-determination components: capacity and opportunity. Capacity refers to a student's knowledge, abilities, and perceptions that enable him/her to be self-determined. Opportunity refers to a student's chances to use his/her knowledge, abilities, and perceptions at school and home. The AIR Self-Determination Student (AIRS) form measures four aspects of self-determination. Two aspects (Things I Do and How I Feel) measure capacity, and two aspects (What Happens at School and What Happens at Home) measure opportunity. The AIR Self-Determination Parent (AIR-P) form measures three aspects of self-determination. One aspect (Things My Child Does) measures capacity, and two aspects (What Happens at Home and What Happens at School) measure opportunity. The AIR Self-Determination Educator (AIR-E) form measures five aspects of self-determination. Three aspects (Knowledge, Ability, and Perception) measure capacity, and two aspects (Opportunity at School and Opportunity at Home) measure opportunity. The AIR Assessments adhere to the learning theory of self- determination as presented in Mithaug, Mithaug, Agran, Martin, and Wehmeyer [9], which suggest that the necessary characteristics of self- determination develop over time as children learn skills and develop attitudes that allow them to engage in self-determined behaviors.

The research methodology utilized for this research was a one-group pretest-posttest design. This methodology involves collecting information on the status of subjects prior to and following implementation of a treatment. The treatment in this research study was the NCSC Curriculum Resource Schema. The intervention phase continued intermittently for nine weeks with unscheduled absences due to weather. Results of the AIR-S,
AIR- P, and AIR-E were scored according to AIR Self- Determination User Scale and Guide [18] to determine if a change in capacity and opportunity for self-determination had occurred.

\subsection{Instrument}

The AIR- S contains 24 questions to measure students' capacity (12 questions) and opportunity (12 questions). The AIR-P contains 18 questions that measure students' capacity (6 questions) and opportunity (12 questions). The AIR-E contains 30 questions to measure students' capacity (18 questions) and opportunity (12 questions).

\subsection{Missing Data}

Across student and parent AIR forms, there existed a small amount of arbitrary missing data. Nonresponse in research interferes with the goal of determining a change in capacity and opportunity. Because of the potential misrepresentative effects of not including all available data in the analysis process, a simple mean imputation [4] was calculated to replace the missing data.

\section{Results}

\subsection{Student Response}

Students were administered the AIR-S prior to intervention. It is important to note that the educator had to read the assessment form to the students and record their verbal responses. Another significant observation was that the student's ability to comprehend the questions was compromised due to each student's cognitive level. This was apparent as some students answered questions voicing the last option read to them in the assessment form. As indicated in Table 1, the results of the AIR-S show a pretest capacity mean score of 43.86 and a posttest capacity mean score of 45.71 . The total difference between pretest and posttest means yielded an increase of 1.85 for capacity for self-determination. The outcomes of the AIR-S establish a pretest opportunity mean score of 45.85 and a posttest opportunity mean score of 52 . The overall difference between pretest and posttest means yielded an increase of 6.15 for opportunity. 
Table 1. Student capacity and opportunity mean scores from pretest and posttest

\begin{tabular}{|c|c|c|c|c|c|c|}
\hline \multirow[b]{2}{*}{ Student } & \multicolumn{3}{|c|}{ Capacity } & \multicolumn{3}{|c|}{ Opportunity } \\
\hline & Pretest & Posttest & Difference & Pretest & Posttest & Difference \\
\hline S1 & 40 & 52 & $(+) 12$ & 54 & 60 & $(+) 6$ \\
\hline S2 & 60 & 52 & $(-) 8$ & 60 & 58 & (-) 2 \\
\hline S3 & $30^{(1)}$ & 60 & $(+) 30$ & $30^{(1)}$ & 60 & $(+) 30$ \\
\hline S4 & 48 & 43 & $(-) 5$ & 49 & 47 & $(-) 2$ \\
\hline S5 & 38 & 50 & $(+) 12$ & 52 & 50 & (-) 2 \\
\hline S6 & 48 & 31 & (-) 17 & 48 & 44 & $(-) 4$ \\
\hline S7 & 43 & 32 & (-) 11 & 28 & 45 & (t) 17 \\
\hline Mean & 43.86 & 45.71 & $(+) 1.85$ & 45.85 & 52 & $(+) 6.15$ \\
\hline
\end{tabular}

\subsection{Parent Responses}

Parents were given the AIR-P prior to and after the intervention and asked to fill out the form and return it to school. As shown in Table 2, the results of the AIR-P indicate a pretest capacity mean score of 16.71 and a posttest capacity mean score of 17.21. The total difference between pretest and posttest mean scores yielded an increase of 3.38 for capacity. The outcomes of the AIR-P establish a pretest opportunity mean score of 40.57 and a posttest opportunity mean score of 49.21. The overall difference between pretest and posttest mean scores yielded an increase of 8.64 for opportunity for self- determination. This missing data also influenced the mean scores for opportunity. The absent data constituted $43 \%$ of parental entries for the pretest opportunity mean score, $14 \%$ of the parental posttest opportunity mean score, and a $29 \%$ of the difference opportunity mean score.

Table 2. Parent capacity and opportunity mean scores from pretest and posttest

\begin{tabular}{|c|c|c|c|c|c|c|}
\hline \multicolumn{4}{|c|}{ Capacity } & \multicolumn{3}{|c|}{ Opportunity } \\
\hline Parent & Pretest & Posttest & Difference & Pretest & Posttest & Difference \\
\hline P1 & 19 & 8 & $(-) 8$ & $39^{(1)}$ & 46 & $(+) 7$ \\
\hline P2 & 12 & 19 & $(+) 7$ & 59 & 60 & $(+) 1$ \\
\hline P3 & $9^{(1)}$ & 18 & $(+) 9$ & $27.5^{(1)}$ & 55 & (+) 27.5 \\
\hline P4 & 20 & 20 & 0 & 56 & 57 & $(+) 1$ \\
\hline P5 & 21 & 24 & $(+) 3$ & 52 & 54 & $(+) 2$ \\
\hline P6 & 19 & 23 & $(+) 4$ & 42 & 56 & (+) 14 \\
\hline P7 & 17 & $8.5^{(1)}$ & 8.5 & $8.5^{(1)}$ & 16.5 & $(+) 8$ \\
\hline Mean & 16.71 & 17.21 & (t) 3.38 & 40.57 & 49.21 & (+) 8.64 \\
\hline
\end{tabular}

\subsection{Educator Responses}

The educator completed the AIR-E for each student prior to intervention. As presented in
Table3, the results of the AIR-E show a pretest capacity mean score of 37.43 and a posttest capacity mean score of 57 . The total difference between pretest and posttest mean scores yielded an increase of 19.57 for capacity for self-determination. The outcomes of the AIR-P establish a pretest opportunity mean score of

29.57 and a posttest opportunity mean score of

40.71. The overall difference between pretest and posttest mean scores yielded an increase of 11.14 for opportunity for self-determination. There are no missing scores for capacity and opportunity in the educator responses.

Table 3. Educator capacity and opportunity mean scores from pretest and posttest

\begin{tabular}{lrrrrrrr}
\hline & \multicolumn{3}{c}{ Capacity } & & \multicolumn{3}{c}{ Opportunity } \\
Educator & Pretest & Posttest & Difference & & Pretest & Posttest & Difference \\
\cline { 2 - 8 } E1 & 27 & 53 & $(+) 26$ & & 28 & 38 & $(+) 10$ \\
E2 & 52 & 69 & $(+) 17$ & & 31 & 42 & $(+) 11$ \\
E3 & 47 & 66 & $(+) 19$ & & 34 & 42 & $(+) 8$ \\
E4 & 40 & 58 & $(+) 18$ & & 31 & 42 & $(+) 11$ \\
E5 & 37 & 57 & $(+) 20$ & & 29 & 39 & $(+) 10$ \\
E6 & 32 & 50 & $(+) 18$ & & 26 & 41 & $(+) 15$ \\
E7 & 27 & 46 & $(+) 19$ & & 28 & 41 & $(+) 13$ \\
& & & & & & & \\
Mean & 37.43 & 57 & $(+) 19.57$ & & 29.57 & 40.71 & $(+) 11.14$ \\
\hline
\end{tabular}

\section{Discussion}

This study sought to determine if the selfdetermination components of capacity and opportunity would differ for students with SCD after nine weeks of the NCSC Curriculum Resource Schema intervention was applied to seven students in an elementary transitional CDC classroom in a rural school district in middle Tennessee. Selfdetermination was measured using the American Institutes for Research (AIR) Self-Determination Assessment, which focused on the capacity and opportunity components of self-determination. Positive gains in mean scores following the nineweek intervention period are evidence that the curriculum approach is worthwhile and beneficial for students with SCD. Furthermore, the Curriculum Resource Schema developed by the NCSC is manageable and easily accessible for educators. This study has shown the ability of the curriculum resource schema to link learning opportunities with grade-level content in preparation for the NCSC assessment. This approach to learning and assessment enables students with SCD to participate in learning opportunities that are aligned with grade level peers. 


\subsection{Limitations}

There were some limitations to this study which may tend to compromise the validity and reliability of the research findings. First, while the one group pretest-posttest design offers simplicity, there are possible events that may increase scores. For example, one or more students may enroll in outside tutoring or therapy. Under these circumstances, it would be difficult to determine if the positive gains in scores are a result of the intervention or the outside experience. Next, maturation may play an unintended role in the demonstration of change in mean scores. The research participations may show progress as a result of maturation, or regression as result of weariness. Another limitation to the pretest-posttest design is that participants completed identical pretest and posttest assessments. This specific implementation of identical assessments may assist the student in scoring better on the second test because of previous practice. Despite the possibility of these limitations, the pretest-posttest design proved to be the most accurate measure for assessing the components of capacity and opportunity of selfdetermination for this small group of students.

\subsection{Implications for Practice and Future Research}

The conclusions of this research study are very promising to educators in the field who are facing the state mandated NCSC as an alternate assessment measure. First, the design of the NCSC Curriculum Resource Schema is very user-friendly for teachers. Second, this curriculum guide assists teachers in providing instruction that focuses on the students' current grade level. Finally, positive gains in mean scores during a nine-week intervention period could provide good evidence that the NCSC Curriculum Resource Schema approach is worthwhile and beneficial for students with SCD.

These research findings lead to more questions about the NCSC Curriculum Resource Schema and its ability to increase the self-determination of students with SCD. Additional research studies focusing on larger populations of students need to be conducted to build a body of knowledge about the research. It would also be interesting to conduct a longitudinal study to determine the effect that the NCSC Curriculum Resource Schema plays on the self-determination of students with SCD over their entire academic career and in their transition from high school to college, career, and community readiness.

\section{References}

[1] Brown, L., Bronston, M. B., Hamre-Nietupski, S., Pumpiam, I., Certo, N., \& Gruenewald, L. (1979). A strategy for developing chronological-age-appropriate and functional curricular content for severely handicapped adolescents and young children. The Journal of Special Education, 13,81-90.

[2] Browder, D. M., Spooner, F., Ahlgrim-Delzell, L., Harris, A., \& Wakeman, S. (2008). A meta-analysis on teaching mathematics to students with significant cognitive disabilities. Exceptional Children, 74, 407- 432.

[3] Collins, B. C., Evans, A., Creech-Galloway, C., Karl, J., \& Miller, A. (2007). Comparison of the acquisition and maintenance of the teaching functional and core content sight words in special and general education settings. Focus on Autism and Other Developmental Disabilities, 22, 220 -23 .

[4] Gemici, S., Bednarz, A., \& Lim, P. (2012). A primer for handling missing values in the analysis of education and training data. International Journal of Training Research, 10(3), 233-250.

[5] Hall, D. (2013). The arts and elementary education: Effects on student learning, motivation, andself-efficacy. Unpublished master's thesis, The Evergreen State College, Olympia, Washington.

[6] Hunt, P., McDonnell, J., \& Crockett, M. (2012). Reconciling an ecological curricular framework focusing on quality of life with the development and instruction of standards-based academic goals. Research and Practice in Severe Disabilities, 37(3), 139-152.

[7] Jameson, J. M., McDonnell, J., Johnson, J. W., Riesen, T., \& Polychronis, S. (2007). A comparison of one-to-one embedded instruction in the general education classroom and one-to-one massed practice instruction in the special education classroom. Education \& Treatment of Children, $30,23-44$.

[8] Kohl, F., McLaughlin, M., \& Nagle, K. (2006). Alternate achievement standards and assessments: A descriptive investigation of 16 states. Exceptional Children, 73, 107-123.

[9] Mithaug, D. E., Mithaug, D. K., Agran, M., Martin, J. E., \& Wehmeyer, M. L. (2003). Self- determined learning theory: Construction, verification, and evaluation. Ed, Mahwah: New Jersey, Lawrence Erlbaum Associates.

[10] The National Center and State Collaborative. (2014). National center and state collaborative project summary. Retrieved August 24, 2014, http://www.ncscpartners.org/ Media/Default/PDFs/Resources/Parents/NCSC\%20Project \%20Description\%2011-1- 13.pdf

[11] National Center and State Collaborative WIKI. (n.d.). Retrieved August 24, 2015 from the NCSC Wiki: 
https://wiki.ncscpartners.org/index.php/Main_Page

[12] National Gateway to Self-determination. (n.d.). What is self-determination? Retrieved February 20, 2015 from http://www.ngsd.org/everyone/what-self-determination

[13] Nietupski, J., Hamre-Nietupski, S., Curtin, S., \& Shrikanth, K. (1997). A review of curricular research in severe disabilities from 1976 to 1995 in six selected journals. The Journal of Special Education, 31,36 -55.

[14] Quenemoen, R. (2008). A brief history of alternate assessments based on alternate achievement Standards. (Synthesis Report 68). Minneapolis, MN: University of Minnesota, National Center on Educational Outcomes.

[15]Snell, M. E. (1997). Teaching children and young adults with mental retardation in school programs: Current research. Behaviour Change, 14, 73-105.

[16] Thompson, S. J., \& Thurlow, M. L. (2000). State alternate assessments: Status as IDEA alternate assessment requirements take effect. (Synthesis Report No. 35). Minneapolis: University of Minnesota, National Center on Educational Outcomes. Retrieved March 30, 2015, from

http://www.cehd.umn.edu/NCEO/onlinepubs/archive/Synt hesis/Synthesis35.html

[17] Wehmeyer, M., \& Schwartz, M. (1997). Selfdetermination and positive adult outcomes: A follow-up study of youth with mental retardation or learning disabilities. Exceptional Children, 63(2), 245- 255.

[18] Wolman, J.M., Campeau, P. L., Dubois, P. A., Mithaug, D. E., \& Stolarski, V. S. (1994). AIR selfdetermination scale and user guide. Zarrow Center for Learning Enrichment, University of Oklahoma. Retrieved from

http://www.ou.edu/content/dam/Education/documents/mis cellaneous/air-self-determination user-guide.pdf

[19] Ysseldyke, J. E., \& Olsen, K. R. (1997). Putting alternate assessments into practice: What to measure and possible sources of data. (Synthesis Report No. 28). Minneapolis, MN: University of Minnesota, National Center on Educational Outcomes. 